\title{
A Sudden Change In Rainfall Characteristics In Amman, Jordan During The Mid 1950s
}

\author{
${ }^{1}$ Mahmoud M. Smadi and ${ }^{2}$ Ahmed Zghoul \\ ${ }^{1}$ Department of Mathematics and Statistics, Jordan University of Science and Technology \\ P.O. Box 3030, Irbid 22110 Jordan \\ ${ }^{2}$ Department of Mathematics and Physics, University of Qatar, P.O. Box 2713 Doha, Qatar
}

\begin{abstract}
This study examines recent changes, trends and fluctuations in the total rainfall and number of rainy days at Amman Airport Meteorological (AAM) station in Jordan during the period 1922-2003. The occurrence of abrupt changes and trends were examined and identified using the Pettitt test, a combination of cumulative sum charts (CUSUM) and bootstrapping and the sequential version of Mann-Kendall rank tests. A sudden change and shift in the average of the total rainfall and annual number of rain days occurred in 1957. Annual total rainfall series from Madaba and Mafraq stations are also analyzed and showed similar change and shift points as that which appeared in AAM station. The analysis prevail a decline in the total rainfall and number of rain days in the second half of the past centaury.
\end{abstract}

Key words: Jordan, Amman, rainfall, abrupt changes, trends

\section{INTRODUCTION}

Large potential studies have been carried out up to date to detect and locate climate changes and trends in different parts of the world by analyzing climate elements such as; air temperature and rainfall records. Some of these studies deal with measurements of temperature and rainfall data for specific meteorological stations due to the importance of its long record lengths, location and reliability ${ }^{[1,2]}$.

Changes in temperature and rainfall in developing countries did not receive enough concern globally and locally even though these countries suffer serious environmental, agricultural and water resources problems. Jordan is one of the ten most well known countries with the lowest levels of water resources and faces severity in water shortage. By the year 2025, it is expected that Jordan will be in the category of having an absolute water shortage ${ }^{[3]}$. Rain in Jordan is the only assured renewable water source. Rain-fed agriculture in Jordan is the most important mode of employment and food production.

Certain studies on rainfall in Jordan and the region have been performed. These studies focused on trend estimation and time series analysis for short record lengths of total rainfall data obtained from different stations. Cohen and Stanhill ${ }^{[4]}$ examined the climate changes in Jordan Valley and concluded a marked decrease in irradiance and a significant reduction in atmospheric transmissivity in the region. In there study, two selected stations, Degania Alef and Sedom Pans stations were considered and total rainfall data from 1916 and from 1936 for the two selected stations respectively. The rate of changes was -0.47 and -0.16 mm per year for Degania Alef and Sedom stations, respectively; however, the rate of changes was insignificant at level of significance 0.05 . Tarawneh ${ }^{[5,6]}$ examined the basic characteristics of drought, duration, intensity and frequency for selected stations in Jordan. Al-Ansari et al. ${ }^{[7]}$ concluded that there was a general decrease in rainfall intensity.

In this study, the historical data of the total rainfall and number of rain days for the AAM station will be analyzed in detail to obtain reliable estimates of the characteristics of rainfall. The rainfall data obtained from the AAM station covers a period of 81 years (1922-2003). Rainfall data for Madaba and Mafraq stations for the period 1938-2002 were analyzed. These meteorological stations were chosen based on the length of the series and the similarity of the topographical characteristics as that of AAM station. The record lengths of these two stations include the detected change point in AAM station; thus, a change point analysis can be done. The three stations are located in the northern part of the country, which is of particular interest due to the total amount of rainfall, agriculture and population. Most of the eastern and southern parts of the country are desert and thus, are rare in rainfall and agricultural activities.

The analyses of rainfall fluctuations of AAM station include annual and monthly total rainfall as well as number of rain days series. The techniques of the Pettitt test and a combination of cumulative sum charts (CUSUM) and bootstrapping were used to detect and locate any abrupt changes. The sequential version of Mann-Kendall rank test and the ordinary regression technique were used to demonstrate any presence of possible trends against the null hypothesis of

Corresponding Author: Mahmoud M. Smadi, Department of Mathematics and Statistics, Jordan University of Science and Technology, P.O. Box 3030, Irbid 22110 Jordan, Fax: (+962)2- 7095014 
randomness. The Mann-Whitney test was used to compare the number of rainy days and total rainfall for two subset series.

Data used: The Amman Airport Meteorological (AAM) station was the main station in Jordan and established in 1922, since British colonization of Jordan. The AAM station has special attention because of its moderate record length, reliability and its location with respect to Jordan and the Middle East. The station lies in the eastern part of the capital city (Amman). The station elevation is $780 \mathrm{~m}$, a. m. s. 1. with Latitude $\mathrm{N} 31^{\circ}$ $59^{\prime}$ and longitude E $35^{\circ} 59^{\circ}$. The mean annual rainfall and temperature are $275 \mathrm{~mm}$ and $12.3 \square \mathrm{C}$, respectively, while the monthly evaporation mean is $51 \mathrm{~mm}$.

Examining the AAM meteorological station history records is necessary in order to rule out the trends and changes induced by site relocations and related changes. However, the lack of resources in the station resulted in the unavailability of enough information. Therefore, very miner changes in site locations within a small area of Amman Airport, which occurred in 1967, 1976, 1980 and 1990, have been reported. It is advantageous to call rainfall records from other neighboring stations in the country having similar topographical characteristics due to the deficiency of enough information about the history of AAM station.

Rainfall data from two stations in Jordan were analyzed, namely Madaba and Mafraq stations. The Madaba station is the nearest station to AAM station and is located to the west south of AAM station. Another important station in the north of the country is the Mafraq station, close to Syria, which is also similar in topographical characteristics to AAM station. The AAM and Mafraq stations are located between the eastern part of the hilly region and the western part of badia. The information concerning the three selected stations, AAM, Madaba and Mafraq, include locations, period of recording data and elevation, are shown in Table 1. Figure 1 shows the geographical location of Jordan and the location of the three selected climatic stations.

\section{MATERIALS AND METHODS}

The pettitt change point test: It has been demonstrated that the Pettitt test is a useful technique for examining the occurrence of abrupt changes in climatic records ${ }^{[8,9]}$. The test was described by Pettitt ${ }^{[10]}$ and can be performed as follows:

First, the statistic $U_{k}$ is calculated using the following equation:

$U_{k}=2 \sum_{i=1}^{k} M_{i}-k(n+1)$,

where $M_{i}$ is the rank of the $i$-th observation when the values $X_{1}, X_{2}, \ldots, X_{n}$ in the series are arranged in

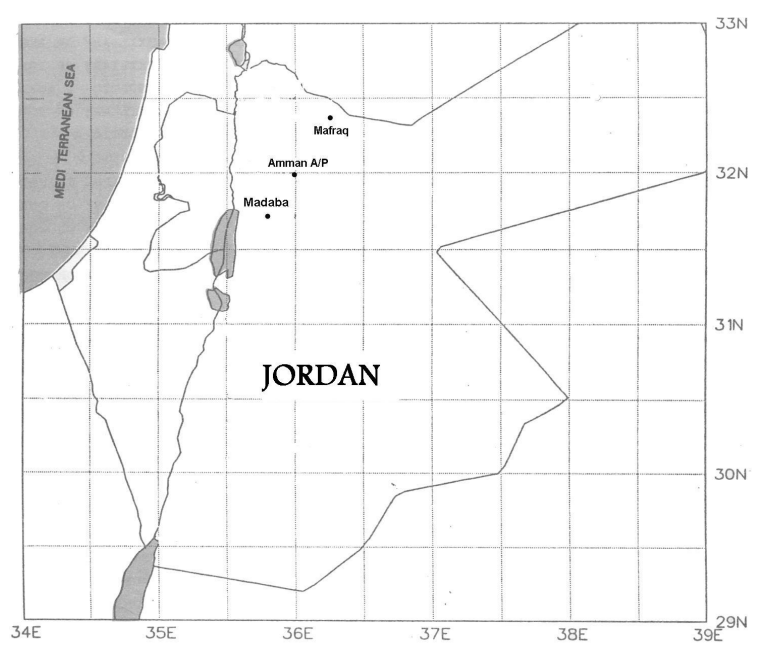

Fig. 1: Locations of Amman, Madaba, and Mafraq stations in Jordan

ascending order. Then the statistical change point test statistic (SCP) is defined as:

$K=\max _{1 \leq k \leq n}\left|U_{k}\right|$

A change point occurs in the series at which $U_{\mathrm{k}}$ attains a maximum value of $K$. The critical value is given by:

$K_{\alpha}=\left[-\ln \alpha\left(n^{3}+n^{2}\right) / 6\right]^{\frac{1}{2}}$

Cumulative sum charts (CUSUM): This procedure was used by Wayne ${ }^{[11]}$ and is used for performing a change point analysis and detection using cumulative sum charts (CUSUM) and bootstrapping. Let $X_{1}, X_{2}, \ldots, X_{n}$ represent the $n$ data points. The cumulative sums $S_{0}, S_{1}, \ldots, S_{n}$ are calculated iteratively as illustrated in the following three steps:

1. Calculate the average

$\bar{X}=\frac{X_{1}+X_{2}+\ldots+X_{n}}{n}$

2. set $\mathrm{S}_{0}=0$.

3. Calculate $S_{i}$ recursively:

$S_{i}=S_{i-1}+\left(X_{i}-\bar{X}\right), \quad i=1,2, \ldots, n$

A sudden change in the direction of the CUSUM indicates a sudden shift in the average. A period where the CUSUM chart follows a relatively straight path indicates a period where the average does not change.

The confidence level can be determined by performing bootstrap analysis. Before performing the bootstrap analysis, the magnitude of change $S_{\text {diff }}$ which is defined as:

$S_{\text {diff }}=S_{\text {max }}-S_{\text {min }}$

Where $S_{\max }=\max _{i=0, \ldots, n} S_{i}$ and $S_{\min }=\min _{i=0, \ldots, n} S_{i}$

Then, the bootstrap analysis can be performed as follows:

1. Generate a bootstrap sample of $n$ units, denoted as $X_{1}^{0}, X_{2}^{0}, \ldots, X_{n}^{0}$, by randomly reordering the original $n$ values. 

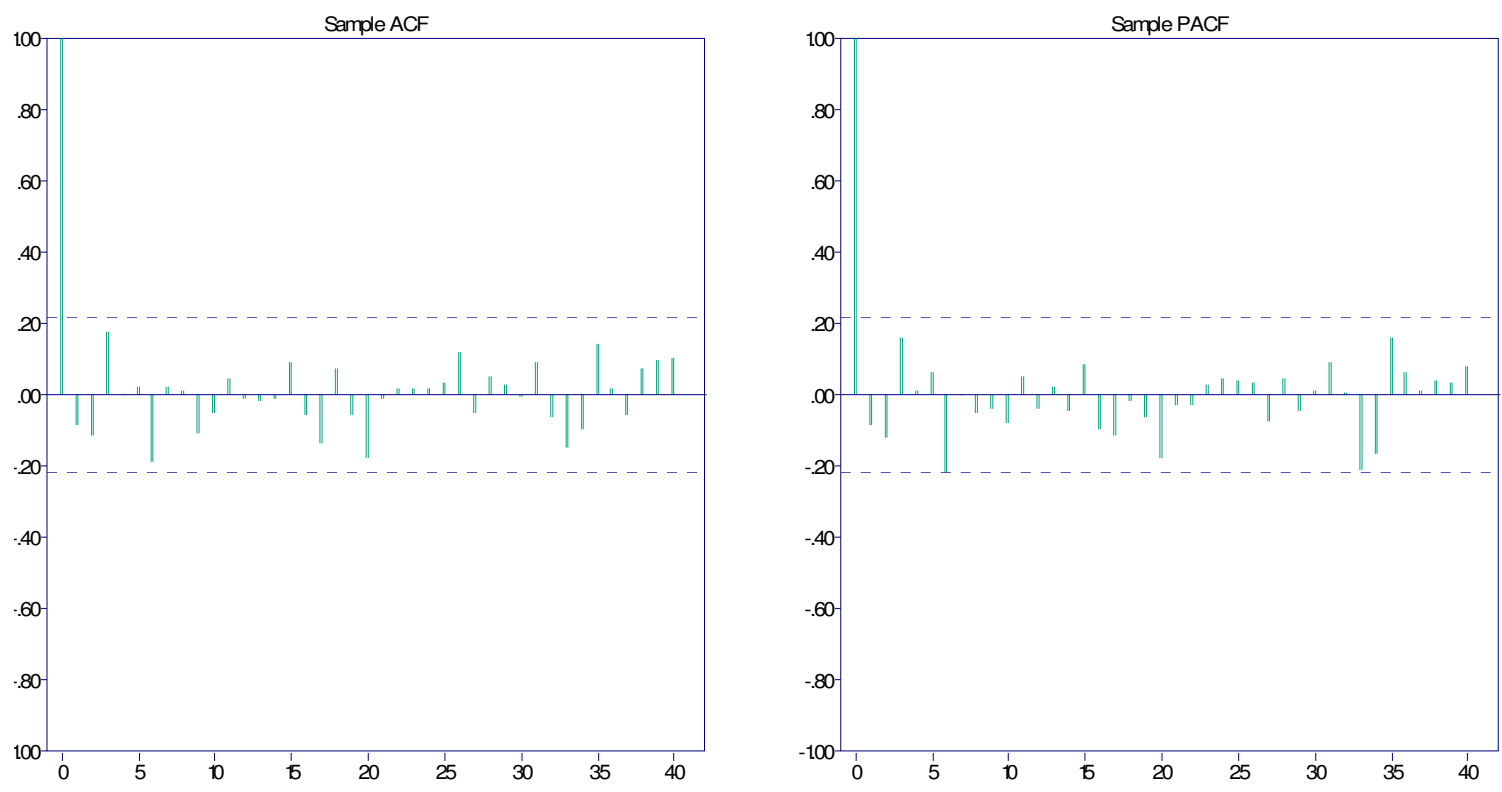

Fig. 2: The sample PACF and ACF of the annual total rainfall series of AAM station

Table 1: Stations location, period, mean, C.V and slope estimates of total annual rainfall of different stations for the period 1938-2002

\begin{tabular}{llllllllll}
\hline Station & Period & Elev & Lat. N & \multicolumn{2}{c}{ Long. E } & Mean & C.V & Slope \\
\hline Mafraq & $1938-2002$ & 683 & 32 & 22 & 22 & 36 & 165 & 0.36 & -0.495 \\
Amman Airport & $1938-2003$ & 779 & 31 & 59 & 35 & 59 & 277 & 0.35 & -1.138 \\
Madaba & $1938-2002$ & 785 & 31 & 43 & 35 & 48 & 349 & 0.37 & -1.360 \\
\hline
\end{tabular}

Table 2: Summary statistics for the total rainfall for the entire period (1922-2003) and the two sub-periods of AAM station.

\begin{tabular}{lllllllllll}
\hline \multicolumn{3}{l}{} & \multicolumn{3}{c}{ 1922-2003 } & \multicolumn{3}{c}{ First Period (1922-1957) } & \multicolumn{3}{c}{ Second Period (1958-2003) } & Mean-1 \\
\hline Season & Mean & Slope & M-K & Mean-1 & S.D & C.V. & Mean-2 & S.D & C.V. \\
\hline Annual & 275 & -0.383 & -1.39 & 290.1 & 84.5 & 0.29 & 263.5 & 95.6 & 0.36 & 0.91 \\
October & 6.48 & 0.042 & 0.16 & 5.37 & 10.33 & 1.92 & 7.30 & 9.75 & 1.34 & 1.36 \\
November & 28.11 & -0.103 & -0.76 & 33.42 & 35.82 & 1.07 & 24.17 & 27.43 & 1.13 & 0.72 \\
December & 46.75 & 0.016 & -0.35 & 50.44 & 41.15 & 0.82 & 44.02 & 44.45 & 1.01 & 0.87 \\
January & 64.49 & -0.003 & 0.07 & 62.96 & 34.78 & 0.55 & 65.62 & 41.78 & 0.64 & 1.04 \\
February & 61.52 & -0.327 & -1.39 & 71.75 & 46.52 & 0.65 & 53.95 & 42.46 & 0.79 & 0.75 \\
March & 43.14 & 0.226 & $2.60^{* * *}$ & 38.31 & 37.92 & 0.99 & 46.7 & 34.25 & 0.93 & 1.22 \\
April & 13.85 & -0.135 & $-2.43^{* *}$ & 15.58 & 16.11 & 1.03 & 12.57 & 23.87 & 1.90 & 0.80 \\
May & 3.47 & -0.018 & $-2.62^{* * *}$ & 3.97 & 7.51 & 1.89 & 3.11 & 5.81 & 1.87 & 0.78 \\
\hline
\end{tabular}

2. Based on the bootstrap sample, calculate the bootstrap CUSUM, denoted as $S_{0}^{0}, S_{1}^{0}, \ldots, S_{n}^{0}$.

3. Calculate the maximum, the minimum and the difference of the bootstrap CUSUM, $S_{\max }^{0}, S_{\min }^{0}$, and $S_{\text {diff }}^{0}$, respectively.

4. Determine whether the bootstrap difference $S_{\text {diff }}^{0}$ is less than the original difference $S_{\text {diff }}$ or not.

5. Iterate the above procedure (1)-(4) $N$ times.

Let $X$ be the number of bootstraps for which $S_{\text {diff }}^{0}<S_{\text {diff }}$, then, the confidence level (CL) at which a change point occurred is,

$\mathrm{CL}=100 \frac{X}{N} \%$

To estimate the location of the change point, define $m$ such that:
$\left|S_{m}\right|=\max _{i=0, \ldots, n}\left|S_{i}\right|$

$\mathrm{S}$ is the point furthest from 0 in the CUSUM chart. The point $m$ estimates the last point before the occurrence of the change point.

The above-mentioned control chart and change point analysis are based on the assumption that the observations are independent and identically distributed. The performance of CUSUM chart deteriorates when the process observations are autocorrelated. Many authors discussed the change point identification for autocorrelated observations. For example, Wayne ${ }^{[12]}$ provided a procedure for detecting a departure from this assumption. Lu and Reynolds ${ }^{[13]}$ investigated CUSUM control charts for monitoring the process generated by first order autoregressive process. Atienze et $a l .{ }^{[14]}$ developed a CUSUM scheme utilizing autocorrelated process observations. 
Lee et $a l .{ }^{[15]}$ considered a CUSUM test for parameter change in time series models. In this work, the autocorrelation was tested and the results showed insignificant autocorrelation structure. Hiple et al. ${ }^{[16]}$ showed that the lag-one serial correlation test is a powerful test when stochastic trends are present for a wide class autoregression, moving average and threshold models. On the other hand, Kendall's test is a powerful test for testing deterministic trends such as linear trends. The test statistics using the lag-1 serial correlation test are 0.084 and 0.129 for the annual total rainfall series and the annual number of rain day's series, respectively. The test statistics using the lag-1 serial correlation test are found to be -1.125 and 0.358 for the Madaba annual total rainfall series and Mafraq annual total rainfall series, respectively. Accordingly, insignificant autocorrelation structure for the observations can be concluded.

Two important identification tools for autoregressive moving average (ARMA) models are the sample partial autocorrelation function (PACF) and sample autocorrelation function (ACF). The sample $\mathrm{PACF}$ and $\mathrm{ACF}$ of the annual total rainfall series are shown in Fig. 2. Insignificant remarkable ACF and PACF at different lags can be noticed. According to the Akaike Information Criterion (AIC) as model selection criteria for ARMA models, the best model with minimum AIC value is the autoregressive model of order zero $(A R(0))$ for the different time series. Thus, applying the classical CUSUM chart to the annual total rainfall series, annual number of rain days, Madaba annual total rainfall and Mafraq annual total rainfall series is statistically justified.

Mann-kendall rank test: This test was found to be useful and widely used for detecting trends in climate and environmental sciences ${ }^{[8,17]}$. The sequential version of the Mann-Kendall rank statistics can be performed using the following steps:

i. The original values of the series $x_{i}$ are replaced by their ranks $y_{i}$ and arranged in ascending order.

ii. The magnitudes of $y_{\mathrm{i}}(i=1, \ldots, n)$ are compared with $\mathrm{y}_{\mathrm{j}}(j=1, \ldots, i-1)$. At each comparison, the number of cases $y_{i}>y_{j}$ is counted and denoted by $n_{i}$.

iii. A statistic $t$ is, therefore, defined as follows

$t_{i}=\sum_{i=1}^{n} n_{i}$

iv. The distribution of the test statistic $t$, under the null hypothesis, is asymptotically normal with the following mean and variance,

$$
E\left(t_{i}\right)=\frac{i(i-1)}{4}
$$

and

$$
\operatorname{var}\left(t_{i}\right)=\frac{i(i-1)(2 i+5)}{72}
$$

v. The sequential values of the statistic $u\left(t_{i}\right)$ are then computed as

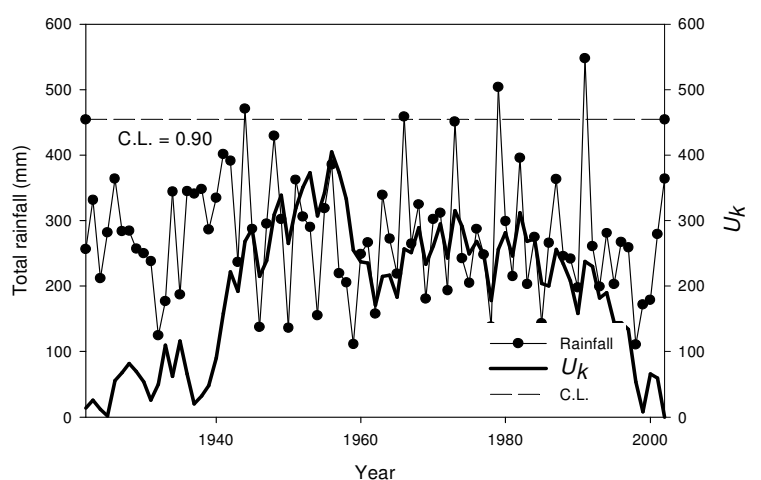

Fig. 3: Application of the Pettitt test to the time series data set of the total annual rainfall of AAM station

$u\left(t_{i}\right)=\frac{t-E\left(t_{i}\right)}{\sqrt{\operatorname{var}\left(t_{i}\right)}}$

vi. Similarly, the values of $u^{\prime}\left(t_{i}\right)$ are computed backward starting from the end of the series.

\section{RESULTS AND DISCUSSION}

In this work, statistical analyses of fluctuations in annual and monthly total rainfall and number of rain days are presented for AAM station. The monthly series for the eight months October-May were constructed for the total rainfall and number of rain days. The following asterisks will be frequently used in the result tables to denote the statistical significance at different levels $(\alpha)$ : for $\alpha=0.1, * *$ for $\alpha=0.05$ and $* * *$ for $\alpha$ $=0.01$.

Rainfall totals: Table 2 presents mean, regression slope estimate and Mann-Kendall (M-K) test statistic for the total annual and monthly rainfall of AAM station for the period 1922-2003. The time series plot and the values of $U_{k}$ statistics determined by the Pettitt test are shown in Fig. 3. Apparently, the change point is not statistically significant; since according to Fig. 3, the peak of the $U_{k}$ plot is relatively close to the critical value at confidence level of 0.9 and suggests a change point in 1957 in the annual total rainfall series. The CUSUM chart also demonstrates similar results and suggests a possible change point around the year 1957. Figure 4 shows trend lines fitted to the sub-periods prior and after the change point in the annual total rainfall series. The Box plots of annual total rainfalls for the two sub-periods are shown in Fig. 5. According to this Box plot, slight shifts were observed in the lower quartile, median and upper quartile in total rainfall. It is also seen that there are certain years associated with high total rainfall during the second periods; these can be considered as outliers.

The mean, standard deviation (S.D) and coefficient of variation (C.V) for each of the two sub-periods are 
shown in Table 2. The decrease in the mean total annual rainfall from first period to the second period was $26.6 \mathrm{~mm}$. The ratio of the annual mean of the total rainfall for the period after the change point relative to that prior to the change point was 0.91 . The rate of decline was determined to be $-3.83 \mathrm{~mm}$ per/decade. According to the Mann-Kendall rank test Table 2, this decreasing trend is not statistically significant. On the other hand, according to the Mann-Whitney test, there is statistical evidence that the median of the total annual rainfall in the second sub-period is lower than that in the first sub-period $(P$-value $=0.000)$.

The results for the monthly mean total rainfall are also displayed in Table 2. An estimate of negative slope is noticed for most months of the rainy season; i.e., November, January, February, April and May. According to the $\mathrm{M}-\mathrm{K}$ test, the decreasing trends are significant in April and May, however, the increasing trend is significant in March. The Mann-Whitney test showed that there is statistical significance that the median in the first period is lower than the median in the second sub-period for the months of February and April.

Analyses were performed on the two selected stations in Jordan, Madaba and Mafraq stations. The correlation between total annual rainfall for Amman and Madaba stations is 0.874 , which is statistically significant at a level of 0.01 . The correlation between total annual rainfall for Amman and Madaba stations is 0.863 , which is statistically significant at a level of 0.01. From this correlation between the stations, one expects a similarity in the changes in the rainfall characteristics. The means, coefficients of variation (C.V) and regression slope estimates of the total annual rainfall for AAM, Madaba and Mafraq stations for the period 1938-2003 are shown in Table 1. The slope estimates are negative for the three stations. AAM station and Madaba station have roughly similar rates of change, which are $-1.138 \mathrm{~mm}$ and $-1.36 \mathrm{~mm}$ per/year, respectively. The Madaba station have highest rate of change, which is $-1.36 \mathrm{~mm}$ per/year. The Madaba station with highest mean rainfall total $(349 \mathrm{~mm})$ and highest elevation $(780 \mathrm{~m}$, a. m. s. 1.) compared to the other two stations. As will be shown later, the annual total rainfall series of Madaba station will exhibit a statistical significant change point in 1957. Mafraq station with lowest rate of change, $-0.495 \mathrm{~mm}$ per year, it is with lowest mean rainfall total $(165 \mathrm{~mm})$ and lowest elevation (683 m, a. m. s. 1.).

The results of the application of the Pettitt test on the total annual rainfall series for Mafraq and Madaba stations are shown in Fig. 6. An indication of a change point is noted in 1957 for the two stations. However, for Madaba station this change point is not statistically significant, since the peak of the $U_{k}$ plot is relatively close to the critical value at the confidence level 0.9. A statistical evidence of abrupt change point in 1957, at level of significance 0.01 , can be noticed for Mafraq

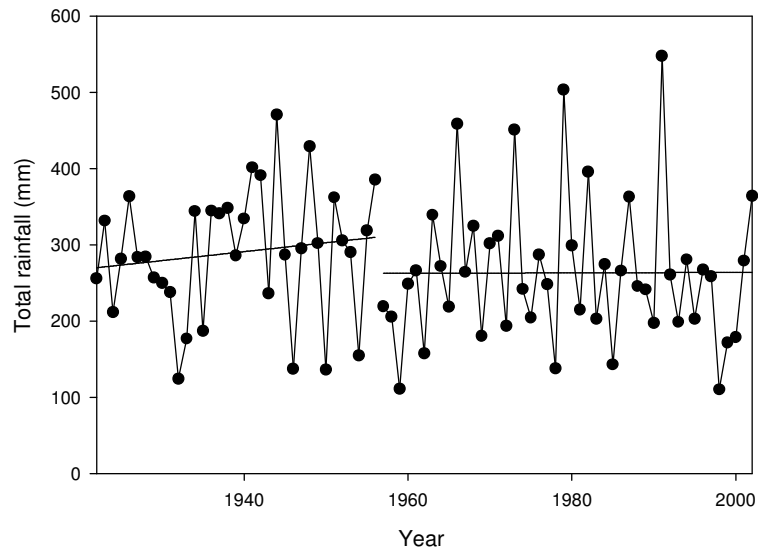

Fig. 4: Linear trends fitted to the sub-periods of the annual total rainfall series of AAM station

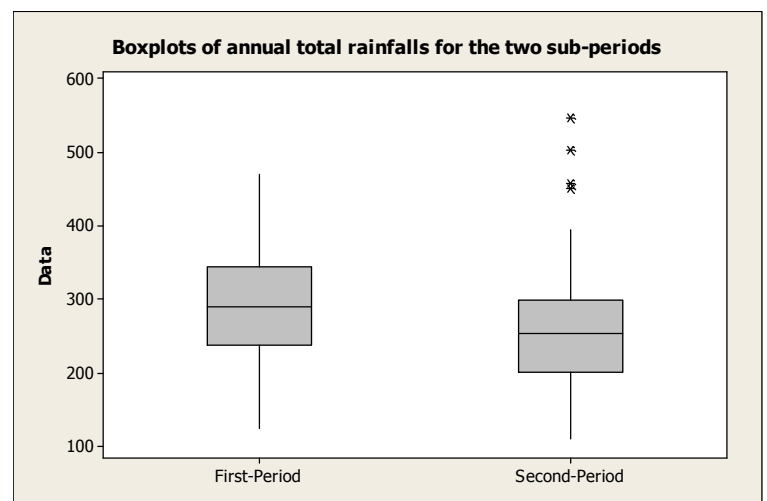

Fig. 5: Box plots for the annual total rainfall for the two sub-periods

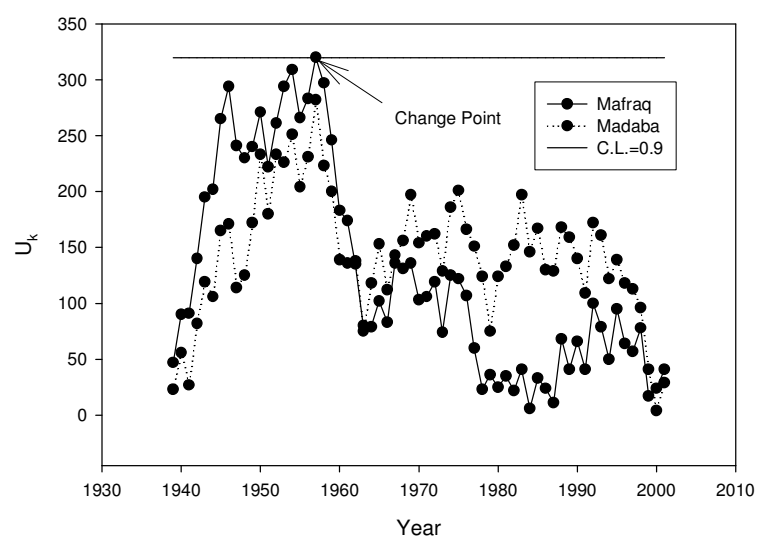

Fig. 6: Application of the Pettitt test to the time series data set of the total annual rainfall for Mafraq and Madaba stations

station. This change point in the two stations is in agreement with the change point in the total annual rainfalls for AAM station.

Number of rain days: For this study, only data from AAM station were considered, since the available number of rain days records for other stations in the country were available only for the second half of the 
Am. J. Environ. Sci., 2 (3): 84-91, 2006

Table 3: Statistical results of the number of rain days for the entire period and the two sub-periods of AAM station

\begin{tabular}{|c|c|c|c|c|c|c|c|c|c|c|}
\hline \multirow{2}{*}{ Season } & \multicolumn{3}{|c|}{$1922-2003$} & \multicolumn{3}{|c|}{ First Period (1922-1957) } & \multicolumn{3}{|c|}{ Second Period (1958-2003) } & \multirow{2}{*}{$\begin{array}{l}\text { Mean }-1 \\
\text { Mean }-2 \\
\end{array}$} \\
\hline & Mean & Slope & M-K & Mean-1 & S.D & C.V. & Mean-2 & S.D & C.V. & \\
\hline Annual & 51.6 & $-0.191^{* * * *}$ & $-2.94^{* * * *}$ & 58.6 & 14.6 & 0.25 & 46.2 & 11.6 & 0.25 & 0.79 \\
\hline October & 2.26 & -0.002 & $-2.23^{* * * *}$ & 2.35 & 2.14 & 0.91 & 2.20 & 2.13 & 0.97 & 0.94 \\
\hline November & 5.35 & -0.017 & $-2.02^{* *}$ & 6.29 & 3.98 & 0.63 & 4.65 & 3.19 & 0.69 & 0.74 \\
\hline December & 8.49 & -0.025 & $-1.98^{* * *}$ & 9.68 & 4.92 & 0.51 & 7.61 & 4.11 & 0.54 & 0.79 \\
\hline January & 1.01 & $-0.046^{* *}$ & $-2.59^{* * *}$ & 12.38 & 4.95 & 0.40 & 10 & 3.33 & 0.33 & 0.81 \\
\hline February & 10.85 & $-0.056^{* *}$ & $-2.75^{* * * *}$ & 12.65 & 5.58 & 0.44 & 9.52 & 4.82 & 0.51 & 0.75 \\
\hline March & 7.96 & -0.010 & -0.90 & 9.12 & 5.94 & 0.65 & 7.11 & 3.48 & 0.49 & 0.78 \\
\hline April & 3.95 & $-0.030^{* * *}$ & $-3.88^{* * * *}$ & 4.68 & 2.78 & 0.59 & 3.41 & 2.43 & 0.71 & 0.73 \\
\hline May & 1.64 & -0.003 & $-3.02^{* * *}$ & 1.97 & 2.58 & 1.31 & 1.39 & 1.57 & 1.13 & 0.71 \\
\hline
\end{tabular}

last century; specifically, after the detected change point in mid of 1950's. Table 3 presents the mean, slope estimate and Mann-Kendall (M-K) test statistic for the series of the annual and monthly number of rain days for AAM station. According to the Pettitt test, $U_{k}$ values were displayed a long with the time series plot are shown in Fig. 7. A statistical evidence of abrupt change point can be noticed in 1957 at level of significance 0.01 . The CUSUM chart is shown in Fig. 8, which also suggests a change point around the year 1957. Using the bootstrap procedure, the confidence level for the change point was found to be close to one. The change point in the number of rain days series was found to be in agreement with the marginal detected abrupt change in the total annual rainfall series in 1957 for the three stations (AAM, Madaba and Mafraq). The Pearson correlation between the total rainfall and the number of rain days was found to be 0.69 . According to the Pearson's correlations test, this correlation was statistically significant $(P$-value $=0.000)$.

The mean, standard deviation (S.D) and the coefficient of variation (C.V) for each of the subperiods are shown in Table 3. The mean annual numbers of rain days are 58.6 and 46.2 for the first and second periods, respectively. The decrease in the number of rain days is 12 days. The ratio of the mean of the sub-period after the change point to that before the change point is 0.79 . The sequential version of the Mann-Kendall rank test was used to display the general trend in the sequences of $u(t)$ and $u^{\prime}(t)$ for the annual mean series, as shown in Fig. 9. A significant long term declining trend in the number of rain days series can be concluded by incorporating the $\mathrm{M}-\mathrm{K}$ test to the data displayed in Fig. 8 and Table 3. The rate of decline was found to be -2 days per/decade. According to the MannWhitney test, there is statistical evidence that the median of the annual number of rain days in the second sub-period is lower than that in the first sub-period $(P$ value $=0.000$ ).

The results for the monthly mean of the number of rain days are given in Table 3. It is noted that the mean for the number of rain days in the second sub-period is always lower than that in the first sub-period for all months. The ratio of the mean of the period after the change point relative to that prior to the change point

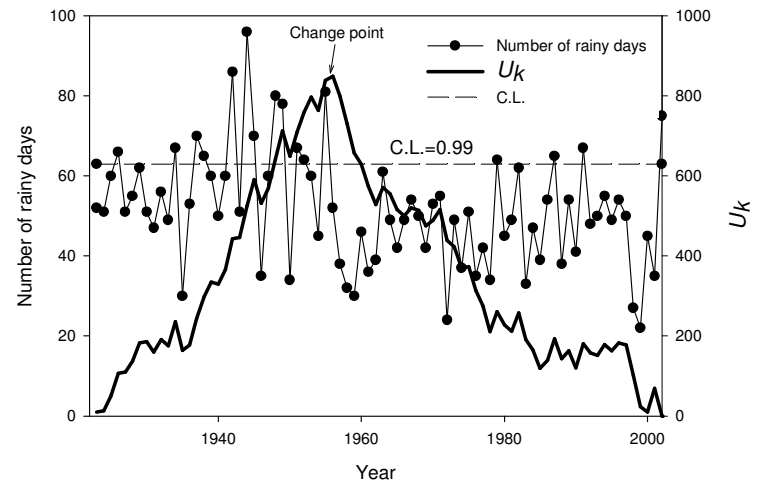

Fig. 7: Application of the Pettitt test to the time series of annual number of rain days of AAM station

for different months are generally between 0.70 and 0.80 . It is seen that all the slope estimates were negatives (Table 3). A significant long term declining trend in the number of rain days for the monthly series can be concluded by incorporating the M-K test to all months of the rainy season except the month of March. The results are shown in Table 3. Using Mann-Whitney test, there is statistical significance that the median in the first period is lower than the median in the second sub-period for the months where the peak of the rainy season occurred; i.e., November, December, January, February and April.

\section{DISCUSSION}

The change point methods used in this work recognize a change in the number of rain days and annual total rainfall in mid of 1950 s and partitions the series into two segments based on statistical criteria. These changes are statistically significant for the number of rain days series of AAM and annual total rainfall for Madaba stations. However, these changes are not statistically significant for the total rainfall series of AAM and Mafraq stations. The Pettitt test and the $U_{k}$ values showed that the peak of the $U_{k}$ plot is relatively close to the critical value. The statistical analysis using box plots, ratios of means after and before the change point, estimates of rates of change, M-K test and Mann-Whitney test showed a decline in the total rainfall and number of rain days in the second half of the last centaury. 


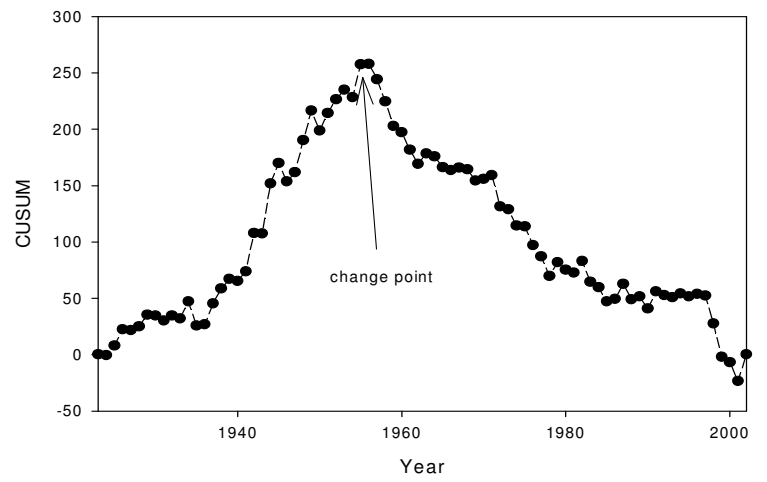

Fig. 8: CUSUM chart for the annual number of rainy days series of AAM station

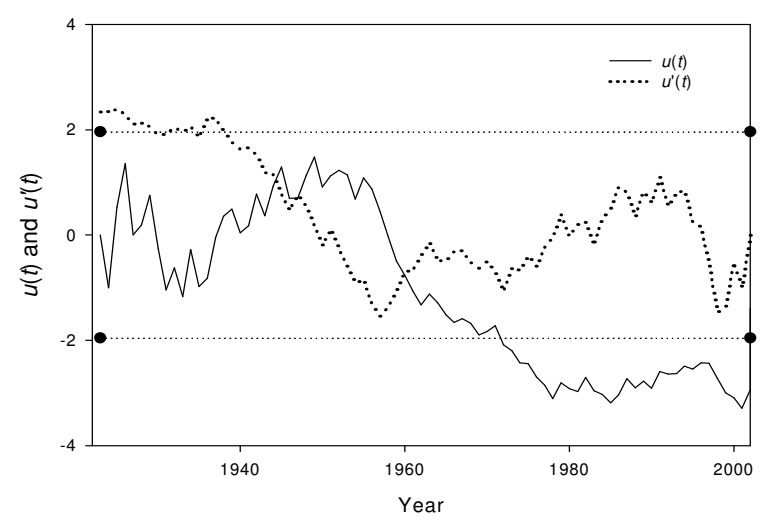

Fig 9: The sequential version of the Mann-Kendall test for the annual number of rain days series of AAM station

It has been noticed that the detected change and declining trend in the rain days series are more pronounced than that in the total rainfall series. A relatively low percent of rainfalls, about $18 \%$ of the total seasonal rainfall, can be noticed during the months of October and March, where total rainfall increases and number of rainy days increases. The increase in the total rainfall and the decrease in the number of rain days, together with the increase in rainfall variability, suggest an increasing trend in rainfall intensity, especially during March month. This month is of particular interest in the rainy season; it contributes to $16 \%$ of the total rainfall.

Concerning the variability and dispersion of annual and monthly rainfall total and number of rain days, using the coefficient of variation (C.V), (Table 2 and 3) that the variability in the second period is larger than in the first period for both data sets, the variability in the second period was found to be larger than that in the first period. The main source of variability could be the occurrence of rare events, of which four statistical outliers were detected after the change point in 1957. These outliers occurred in the rainfall seasons for the years 1966/1967, 1973/1974, 1979/1980 and $1991 / 1992$. On the other hand, no outliers were detected during the first sub-period before the change point in 1957.
The climate of Jordan is predominantly of the Mediterranean type. The rainfall occurs mainly in winter season with its heavy falls in January and February and depends on the weather conditions. The annual rainfall has close relation with zones. The rainfall amount decreases as you go from west to east and from north to south. The general trends of rainfall in the Middle East can be explained on the basis of the region of the tropical high pressure, of which Jordan is located on its northern edges, This affects the trajectory and movement of low atmospheric depressions that cross the Mediterranean. Some areas that are located on the margins of the trajectories of low atmospheric depressions may become far away from these trajectories, which causes a decreased regular cyclonic rainfall in these places.

The impact of a decline in the rainfalls resulted in serious effects in the drought and desertification ${ }^{[5,6]}$. Most rainfall averages in Jordan meteorological stations were smaller than $600 \mathrm{~mm}$. Also, most public and water resources projects occupy theses areas. Even though most negative slope estimates are statistically insignificant, however, from scientific point of view, they have serious effects on drought, desertification and agriculture. For example, for Mafraq station, the mean annual rainfall was $165 \mathrm{~mm}$ and the rate of change -0.5 $\mathrm{mm}$ per year. This may result in a serious effect on drought, desertification and the seeds planting industries in this region.

\section{CONCLUSION}

The following concluding remarks can be outlined based on the results presented in this work:

* The change point methods recognize a change in the annual number of rain days and annual total rainfall in mid of 1950s. These changes are statistically significant for the number of rain days series of AAM and the annual total rainfall of Madaba stations.

* The analysis prevail a decline in the number of rain days and total rainfall in the second half of the last centaury in the AAM station.

* A larger variability in the rainfall was noticed in the sub-period after the change point. A possible source of variability could be the occurrence of rare events, where four statistical outliers were detected after 1957.

* Due to the relatively low amount of rainfall in the region, the impact of a decline in the rainfalls may result in serious effects in the desertification, drought, water resources and agriculture.

* The findings of this study are of particular interest to Jordan and south of Syria and should be taken into consideration by policy makers on environment, agriculture and water resources. It is worth mentioning that the results of this work can be considered as only partially conclusive. Further 
research should examine numerous long series of meteorological data available in Middle East. It is also recommended to focus on other climate variables associated with rainfall characteristics.

\section{REFERENCES}

1. Camuffo, D., 1984. Analysis of the series of precipitation at Padova, Italy. Climate Change, 6: 57-77.

2. Katsoulis, B.D., 1987. Indications of change of climate from the analysis of air temperature time series in Athens, Greece. Climate Change, 10: 6779.

3. Yusuf, M., 1998. Jordan facing water shortage. The Royal Hashemite Court. http://www.kinghussein. gov.jo/geo_env4.html.

4. Cohen, S. and G. Stanhill, 1996. Contemporary climate change in Jordan Valley. J. Appl. Meteorol., 35: 1051-1058.

5. Tarawnwh, S., 1999. Drought analysis of desert and badia of Jordan. Abhath Al-Yarmouk, Basic Sci. Engg., 8: 117-145.

6. Tarawnwh, S., 2000. Drought analysis of selected rainfall stations in Jordan. Dirasat, Engg. Sci., 27: 77-94.

7. Al-Ansari, N., E. Salameh and H. Al-Omari, 1999. Analysis of rainfall in the badia region, Jordan. Research Paper No. 1, Al-al-Bayt University, Jordan.

8. Sneyers, R., 1990. On the statistical analysis of series of observations. WMO Technical Note 143. WMO No. 415, TP-103, Geneva, World Meteorological Organization. Geneva, pp: 192.
9. Aondover, T. and M. Woo, 1998. Changes in rainfall characteristics in northern Nigeria. Intl. J. Climatol., 18: 1261-1271.

10. Pettitt, A.N., 1979. A non-parametric approach to the change point problem. Appl. Stat., 28: 126-135.

11. Wayne, T.W. 2000a. Change-point analysis: A powerful new tool for detecting changes. http://www.variation.com/cpa/tech/changepoint.ht ml. Submitted to Quality Engineering.

12. Wayne, T.W. 2000b. A pattern test for distinguishing between autoregressive and meanshifted data. http://www.variation.com/cpa/tech/ changepoint.html. Submitted to Quality Engineering.

13. Lu, C. and M.R. Reynolds, 2001. CUSUM charts for monitoring an autocorrelated process. J. Qual. Technol., 33: 316-334.

14. Atienza, O.O., L.C. Tang and B.W. Ang, 2002. A CUSUM scheme for autocorrelated observations. J. Qual. Technol., 34: 187-199.

15. Lee, S., J. Ha, O. $\mathrm{Na}$ and $\mathrm{S} . \mathrm{Na}, 2003$. The CUSUM test for parameter change in time series models. Scan. J. Stat., 30: 781-796.

16. Hipel, K.W., A.I. Mclead and P.K. Fosu, 1985. Empirical Power Comparisons of Some Tests for Trend. In Statistical Aspects of Water Quality Monitoring. Eds. A.H. El-Shaarawi and R.E Kwaitkowski, Elsevier Science Publications B.V., pp: 348-362.

17. Kadiolgu, M., 1997. Trends in surface air temperature data over Turkey. Intl. J. Climatol., 17: 511-520. 